\title{
INTIMIDAD Y PROPIEDAD INTELECTUAL EN LAS REDES SOCIALES: EL CASO COLOMBIANO ${ }^{2}$.
}

\author{
PRIVACY AND INTELLECTUAL PROPERTY IN THE SOCIAL NETWORKS: \\ THE COLOMBIAN CASE.
}

Recibido: Enero de 2012 - Revisado: Febrero de 2012 - Aceptado: 30 de Mayo de 2012

Por: Hugo Nelson Castañeda Ruiz.

\section{RESUMEN:}

Los abusos que se hace del derecho a la información en internet y especialmente en las Redes Sociales Virtuales (en adelante RSV) son constantes y la posibilidad de restringirlos es minima. Todo parecería indicar que en el mundo virtual no existirá la censura, pero se evidencia todo lo contrario. Muchos grupos de presión, entre ellos quienes buscan la defensa de intereses económicos, han instado a los gobiernos, como el colombiano, y a las empresas de la web (incluidas las RSV) para que constituyan mecanismos de control de todo lo que se difunde por internet y evitar atentados contra el honor, la intimidad y la propiedad intelectual, pero los métodos (legales o de facto) que se han implementado se convirtieron en una forma de censura de las expresiones creativas que reduce la disponibilidad de información y paradójicamente la libertad individual. Para demostrar lo anterior, en escrito se utilizó técnicas de estudio documental en los que se pudiera constatar la influencia de las RSV en el Derecho.

\section{PALABRAS CLAVE:}

Economía de la información, propiedad intelectual, redes sociales virtuales, intimidad y Copyleft.

\section{ABSTRACT:}

Abuses of the right to information on the Internet and especially in virtual social networks (VSN from now on) are constant and the possibility of restricting them is minimal. Everything would seem to indicate that in the virtual world there is no censorship, but there is evidence of the opposite. Many groups, including those who seek the defense of economic interests, have urged Governments, such as the Colombian one, and the Web companies (including the RSV) so that they constitute control mechanisms of everything that is spread via the Internet and prevent the attacks against honor, privacy, and intellectual property, but the (legal or de facto) methods that have been implemented have become a form of censorship of creative expressions that reduces the availability of information and paradoxically the individual freedom. In order to prove this, techniques of documentary study were used, in which the influence of the VSN in the Law, could be established.

\section{KEY WORDS AND EXPRESSIONS:}

Economy of the information, intellectual property, virtual social networks, privacy, and Copyleft.

\footnotetext{
${ }^{1}$ Abogado de la USB Seccional Medellín - Colombia, Especialista en Responsabilidad Civil de la Universidad Autónoma Latinoamericana, candidato a Magister en Derecho y Economía de la Universidad de Buenos Aires (Argentina), docente de la Universidad San Buenaventura Seccional Medellín - Colombia y co-investigador del proyecto "Redes Sociales Virtuales, el buen Uso", descrito en la cita anterior. Correos electrónicos: hugo.castaneda@usbmed.edu.co; hugonelsoncastanedaruizam@gmail.com.
} 


\section{Introducción.}

Este trabajo abordará la importancia de la información para el desarrollo de la humanidad y los retos que el manejo de ésta supone para las redes sociales virtuales (RSV), V. gr., cuán útiles serian en la actualidad los conocimientos que se perdieron fruto del incendio de la Biblioteca de Alejandría en el año 48 a.C. (Mejía, 2001).

La información se obtiene a través de los sentidos (audición, visualización, tacto, gusto y olfato) y por cualquier fuente (esto es, por otros seres humanos o por la naturaleza). La persona que consigue los datos puede utilizarlos para sí o puede transmitirlos a terceros, a través de una serie de símbolos, señas o sonidos que siguen ciertas reglas que el receptor interpreta y que se le da la denominación de lenguaje.

Es de anotar que el proceso de obtención de información goza de una característica primordial y es la subjetividad del receptor. Éste le da un significado que puede ser diferente al que le dé otro receptor, además, el uso que le da a la misma, también puede ser diverso y diferenciado, valga el siguiente ejemplo que es extraído parcialmente del teorema de Amartya Sen denominado como imposibilidad del liberal paretiano: una publicidad que utilice escenas de desnudos puede tener un significado diferente para un moralista o puritano y para un libertario. El primero se sentirá mal por haber visto dicha publicidad e incluso dirá que la misma ocasiona un perjuicio social, teniendo presente su ideal o modelo de sociedad, y que no debería emitirse; en cambio el segundo maximizará su felicidad y dirá que la publicidad expresa la libertad de sus creadores, lo cual es bueno para la sociedad, teniendo en cuenta su ideal (Aguiar, 2008, p. 91).

No se quiere entrar aquí en discusiones sobre lo que es bueno o malo, eso no es asunto de este texto, lo que se quiere resaltar aquí es la divergencia en las interpretaciones dadas por los receptores cuando son expuestos a la misma información.

Otro asunto interesante es la velocidad con que la información se presenta a los seres humanos. Este tema lo ha trabajado Paul Virilio, un filósofo y arquitecto francés, quien creó una teoría denominada "Dromologia", en la que explica cómo la velocidad con la que se transmiten los datos ha aumentado desde la antigüedad hasta nuestros tiempos, todo ello en parte por la revolución de las tecnologias de la información, pero con éstos avances también se crean nuevos accidentes o catástrofes, como sería el caso del descarrilamiento fruto de la invención de los trenes, o el naufragio con la invención de los barcos.

Para clarificar un poco este asunto, es interesante analizar cómo Virilio (1995, p. 34) entiende la dromología o estudio de la velocidad: en la antigüedad la velocidad era lenta, conocer noticias de otras lugares se llevaba mucho tiempo, lo máximo con lo que se contaba era con un Trirreme, la embarcación más ágil de la época, ahora, con el mejoramiento de los medios de transporte y con internet, llevar las noticias de un lugar a otro es cosa de segundos. De igual forma narra el autor la relación que existe entre velocidad y poder, en donde los ejércitos de aquellos países que son más rápidos, resultan ser los más poderosos (Virilio, 1998, p. 47 - 48). 
Se puede ilustrar la relación entre velocidad e información con el caso de la India, en donde es posible tramitar ante el gobierno, permisos o documentos a través de internet, evitando el contacto directo con los funcionarios, lo cual disminuye los tiempos del trámite y la posibilidad de casos de corrupción (Higueras, 2005, "caos circulatorio" parr. 1).

Ahora bien, vistas las magnitudes de la información, es menester indicar que en el presente trabajo se estudiará los impactos de éste en las RSV y cómo dicha situación influye en las dinámicas jurídicas colombianas.

Lo anterior es importante ya que algunos autores, como Paul Virilio, anuncian aspectos negativos mirando prospectivamente el desarrollo de internet, éste autor considera que la humanidad se encuentra abocada a un accidente de dimensiones mundiales y pone como antecedente la crisis financiera de 1987, el cual fue "resultado de la puesta en funcionamiento del program trading para la cotización automática de los valores, en Wall Street" (Virilio, 1997, p. 91).

Dentro de los impactos podemos destacar aquellos relacionados con los buenos usos y las malas utilizaciones de estos medios. Por buenas prácticas entendemos aquellas que tienen alguna funcionalidad que no dañen o perjudiquen a los seres humanos, como las posibilidades de entretenimiento, negocios, movimientos políticos, académicos, aprendizaje de idiomas, etc.

Dentro de los aspectos negativos encontramos la difamación, la obtención ilícita de información, la organización de grupos criminales por intermedio de estas herramientas y las adicciones generadas por las RSV, entre otras.

La consecución ilegal de datos, es una de las consecuencias negativas de la información que circula en las RSV, y ha generado alternativas que pueden ligarse a los buenos usos, de los cuales caben destacar dos de ellos: el primero está relacionado a las dinámicas de la propiedad intelectual v. gr. el libre licenciamiento y el segundo, ligado a la protección del derecho a la intimidad personal y familiar, como son los mecanismos de colaboración judicial y los sistemas de seguridad que se han implementado en las RSV, en las cuáles las mismas personas deciden qué revelar y quiénes pueden tener acceso a la información allí contenida.

La finalidad del siguiente artículo es resumir la información encontrada para el marco referencial de la investigación y que servirá de insumo para la construcción del informe final de investigación. De igual forma se enunciará uno de los resultados de la muestra de investigación, esto es, el atinente al conocimiento de los estudiantes de la Universidad de San Buenaventura acerca del libre licenciamiento.

En los capítulos siguientes el lector encontrará una breve descripción de la metodología empleada para este trabajo, los hallazgos y discusiones y las conclusiones de todo este trabajo. 


\section{Metodologia.}

Este artículo parte la investigación en redes sociales virtuales, los buenos usos, que desarrolló el grupo de investigación GIDPAD de la Universidad de San Buenaventura Seccional Medellín. Para la investigación se tuvo como procedimiento la realización de una búsqueda documental en bases de datos y en bibliotecas de la ciudad y también se utilizaron encuestas que se hicieron a estudiantes, docentes y empleados de la Universidad. Una de las preguntas que se hizo es si los diferentes estamentos de la universidad conocian acerca de los libres licenciamientos, pero los resultados fueron negativos, como se mostrará en los hallazgos. A pesar de ello, en las pesquisas documentales se hallaron documentos que en parte explican el fenómeno encontrado y además, muestran como las redes sociales e internet han sido una influencia en el mundo para cambiar o morigerar el sistema tradicional de propiedad intelectual, y este escrito muestra lo encontrado y además, defiende (esto para someterlo a discusión), las modificaciones que varios sectores vinculados al copyleft vienen sugiriendo respecto de éste tipo de derechos sobre las creaciones.

\section{Resultados - discusiones.}

La propiedad es un elemento muy importante en el desarrollo de la humanidad, aunque también fue y sigue siendo, un factor de inestabilidad politica y social. La propiedad implica la explotación exclusiva de un bien o servicio. La persona que lo posee puede disponer de éste, utilizarlo y transformarlo, con la facultad de apartar a otras personas de su uso.

Pero, ¿sobre qué tipo de bienes o servicios puede obtener la propiedad una persona? Si se estuviera en un estado de naturaleza, las personas pueden ser propietarias de cualquier cosa que obtengan de la misma (incluida la propiedad sobre otras personas a través de la esclavitud, ya que, en ésta situación, no existe algún tipo de autoridad que lo impida), de forma pacífica o no, a través de intercambios voluntarios o no, siempre y cuando pueda defender de terceros dicha pertenencia. Pero esta noción, que puede parecer arcaica y a su vez tan obvia, puede aplicarse en la actualidad, con algunas modificaciones, esto es, alguien puede ser propietario de un bien o servicio si lo saca del estado de naturaleza en el que se encontraba (siempre y cuando el objeto o servicio sean lícitos) o puede ser propietario a través del intercambio voluntario de bienes, pero debe ser capaz de defender dichos bienes (a través de las instituciones estatales establecidas para ello, v. gr. Jueces o institución policial) del apoderamiento de terceros, de lo contrario la propiedad podría ser otorgada a otra persona, $\mathrm{v}$. gr., la prescripción adquisitiva, en la que una persona que tenga la posesión de un bien, pero sin el título que lo acredite como titular del derecho, luego de transcurrido un tiempo (que en Colombia son 10 años) y luego de cumplir y demostrar algunos requisitos exigidos por la ley, puede convertirse en su legítimo propietario.

De todas las formas jurídicas para adquirir el dominio o propiedad de algo, la de mayor importancia, en las economías modernas, basadas en el mercado, es la transacción. En este aspecto resulta importante las tesis de R. Coase (1992), escrita y publicada en el año de 1960 en la revista "The Journal of Law and Economics" en la que sostiene que lo mejor para las sociedades es el intercambio voluntario de bienes y servicios o de estos por dinero, por cuanto 
genera equilibrios eficientes, en el cual las personas que valoran más los bienes o servicios terminan obteniéndolos y las partes implicadas en éste proceso maximizan su utilidad y a su vez, aumentan el beneficio social, pero para que esto ocurra frecuentemente, debe existir un marco institucional que reduzca los costos de transacción e incentive las prácticas que permitan internalizar las externalidades.

Un ejemplo de lo anterior es la información, la cual es tomada por parte de la economía tradicional como una falla del mercado o como un costo de transacción siguiendo a Ronald Coase (1992), pues "descubrir con quién deseamos transar, informar a la gente que deseamos intercambiar y en qué términos, conducir negociaciones que lleven a un convenio, redactar el contrato, llevar a cabo la inspección necesaria para asegurarnos de que los términos del contrato se observan" (p. 99). Para llevar a buen fin lo pactado en una negociación es necesario prever todas las situaciones descritas, que no son más que información relevante para las partes.

En la concepción tradicional, el Estado debe intervenir para corregir las fallas del mercado, entre ellos la de información, entendida como externalidad, Coase (1992) no escapa del todo a éste planteamiento, sugiere que en ocasiones es importante la intervención estatal, por ejemplo las leyes o decisiones administrativas gubernamentales que generen eficiencia en la negociación (p. 101), y en otras no, pues "no hay razón para suponer que las regulaciones zonales y restrictivas, realizadas por una administración falible sujeta a presiones políticas y operando sin el aliciente competitivo, será necesariamente siempre aquella que incremente la eficiencia con que opera el sistema económico" (p. 100-101).

Y así se hizo durante muchísimo tiempo, se sabe por ejemplo que obtener la información resulta más costoso que divulgarla (Villota Hurtado, 2008, p. 29), el ejemplo clásico es el de las películas, en el que hacerla resulta más costoso que transmitirla, pues los espectadores pueden ir al cine, comprar la película u obtenerla sin autorización de los autores mediante mecanismos informales e incluso, de forma contraria a derecho, pero, para hacerla, se requiere tiempo y presupuesto. Esto mismo se aplica a los medicamentos y a las demás cosas que resulten de la invención humana. Además, se debe tener en cuenta los costos hundidos que trae la publicidad (Bergara, 1999, p. 30-34) para la industria cinematográfica, pues si se quiere generar mejores utilidades se debe hacer que el público conozca de la existencia del film y lo adquiera.

Si no se otorgara algún tipo de protección a la obtención de información, no habría incentivos fuertes que permitieran la creación de invenciones y además, se dificultarian los negocios. Por esto, los Estado han aplicado varios mecanismos, para incentivar la producción de información, por ejemplo, para el mercado de valores ha generado una serie de cargas $u$ obligaciones para las empresas que deseen emitir títulos, como por ejemplo, la elaboración y difusión de prospectos, documentos en donde se consignan datos financieros de las firmas y de las inversiones que deseen financiar con la emisión (sea de renta fija o variable), aminorando los problemas de asimetría de la información y facilitando la consecución de negocios. Otro incentivo creado fue el de la propiedad Intelectual, en el que los Estados, sobre todo los europeos, desde hace mucho tiempo intentaron otorgarle una protección a algunas personas sobre los bienes fruto del intelecto, como si se tratara de una propiedad privada, en 
la que los autores u otras personas podrían autorizar su distribución y venta.

Como bien se sabe, la propiedad intelectual comienza luego del surgimiento de la imprenta creada por Johann Gutenberg. Los impresores del siglo XVI buscaron protección frente a las copias de los libros y los gobiernos aceptaron protegerlos creando monopolios legales para la explotación de las obras. "En Florencia y Venecia se concedieron derechos exclusivos para poner en práctica invenciones antes del 1500" (Sherwood, 1995, p. 35) y antes de la aparición de estas formas de protección, otorgamiento de monopolios, habian prácticas como los secretos comerciales, en el cual el know how sólo era transmitido entre generaciones de una misma familia.

Lo anterior se relaciona directamente con la economía de la información, pues ésta consiste en el estudio de las "relaciones entre agentes económicos en situaciones en las que hay asimetrías de información entre ellos y modelar procesos en los que hay que tomar decisiones cuando la información disponible es incompleta" (Usátegui, 2000, p. 6), todo en beneficio de la innovación y la posibilidad de realizar negocios. Dentro de esto se encuentra la propiedad intelectual que, como ya se había comentado, es un mecanismo que busca incentivar la creatividad humana, pero, a veces no funciona de esa manera, ocasionando lo que se conoce como "tragedia de los anti-comunes", esto es, un "problema de definición de derechos de propiedad que se exacerba con el poder de mercado, y que hace que la ineficiencia asociada con el ejercicio de dicho poder se magnifique" (Coloma, 2003, p. 180) ocasionando una subutilización de la producción y desincentivando la innovación y por consiguiente, elevando el costo social, ya que son pocas las personas que tendrian acceso a éste, lo cual lo convierte en un punto subóptimo, valga el ejemplo de Canavese (2007):

Algunos descubrimientos científicos necesitan hacer uso de otros hallazgos previos que se han patentado. Para avanzar en el nuevo descubrimiento deben pagarse licencias a quienes detentan patentes de esos descubrimientos previos. Quienes detentan esas patentes tienen derechos de exclusión que pueden llevar a una actividad de investigación y desarrollo menor que la eficiente desde el punto de vista de la sociedad. (p. 35.

Otra de las dificultades de la propiedad intelectual fue presentada por Sthepan Kinsella (2001, p. 42). El asunto se encuentra relacionado con el uso que la persona que adquiere el bien o servicio, e. g. quien compra un disco, un libro o una película, hace de él, pues no tendría la libertad de utilizarlo en lo que voluntariamente disponga, no podría copiarlo, ni podría sacar provecho económico, entonces, ¿Quién compra el producto o servicio sería dueño de qué? Además, Si el que adquiere el producto del intelecto no lo puede modificar sin la aquiescencia de quién lo creó o no lo puede duplicar sin la autorización expresa de éste, entonces ¿dónde quedan todos los derechos de quienes fungen de dueños?...

Derecho a La Información y Libertad de Expresión En Las RSV.

Con el surgimiento del world wide web y el lenguaje html gracias a Sir Timothy Berners-lee, y con el "boom" de los navegadores, se abrió la posibilidad para que personas de todo el mundo tengan acceso a la información y la aparición de las RSV masificó aún más esa situación. Ahora las personas no sólo obtienen información, pueden modificarla, duplicarla, 
aprovecharla, etc.

Pero qué se entiende por RSV, Mateos-Aparicio (2012, Introducción, párr. 1) diferencia éstas de los Sitios de Redes Sociales (SRS), indicando que la primera se refiere a sólo relaciones de individuos y las SRS son las infraestructuras, en éste caso las páginas donde se alojan las RSV.

Pero pese al intento que se hace de diferenciarlas, que es válido, éste trabajo asume ambas acepciones como partes integrantes de las RSV, por lo tanto, entiéndase incluidos dentro de éste concepto los sitios web que permiten la interacción, así como las relaciones interpersonales que se generan en estas, como quiera que, la interacción social generada, al menos en la intensidad que se tiene en la actualidad, no se hubiera conseguido sin la herramienta que lo permite, esto es, sin las páginas web que fungen como redes. Pero hay un tercer elemento que es transversal y por lo tanto que cohesiona los ya descritos y es la "libertad de información y expresión", pues las RSV fueron creada para facilitar la comunicación, las relaciones sociales y por ende el intercambio de datos, esto es, para aumentar la disponibilidad de información, lo cual es una característica que Shapiro y Varian (1998, p. 114) consideran común a la mayoría de los avances tecnológicos surgidos a partir del siglo XX.

Para contextualizar un poco la afirmación anterior, recuérdese que desde los orígenes de internet, éste ha servido como herramienta que facilita el acceso a la información de todo tipo. Diversos grupos sociales y politicos, e incluso, organizaciones al margen de la ley, tienen en internet información que cualquier persona podría acceder. Esta libertad característica de internet hizo que en el año 1996 John Perry Barlow escribiera la "Declaración de Independencia del Ciberespacio" (Pérez Luño, s.f., p.108) comunicándole a los Estados que internet está fundada en la libertad de expresión y que de esa forma debe continuar. Pero las cosas no terminan ahí, pues en el año 2011, las Naciones Unidas (ONU), la Organización para la Seguridad y la Cooperación en Europa (OSCE), la Organización de Estados Americanos (OEA) y la Comisión Africana de Derechos Humanos y de los Pueblos (CADHP) emitieran una "Declaración Conjunta sobre Libertad de Expresión e Internet" (Organización de Estados Americanos, 2011), en el que la mayoría de países del mundo se comprometen a garantizar la libertad de expresión en la web.

En este contexto de libertades que envuelve a la web, las RSV fueron creadas y nutridas y ésta dinámica supone múltiples retos para la economía, tal y como lo afirma Alegre (2010, p. 13) retomando a Benkler, se está creando una "economía en red de la información", basada en la colaboración o cooperación voluntaria, basados en un esquema de reciprocidad que podría ser en algunos casos más eficientes que el modelo estricto de propiedad intelectual, o como afirma Gonzalez - Alorda (2012):

Hay numerosas empresas que están usando inteligentemente la tecnología para desarrollar nuevos sistemas de trabajo colaborativo, desde gigantes como Google, en donde se montan y se desmontan con agilidad equipos de trabajo pequeños y autónomos... La colaboración no es un descubrimiento. Es simplemente una capacidad que ahora resulta particularmente necesaria, debido a que la estrategia que el mercado está pidiendo es la innovación. Y se 
podría afirmar que hoy día la principal diferencia entre las empresas que "hablan de innovación" y las que "innovan de verdad" es la cultura de colaboración que logra objetivos tan ambiciosos como... escapar de Alcatraz. (párr. 20 - 21).

Este modelo de cooperación o colaboración también se ve reflejado en las RSV, e.g. en Facebook se pueden encontrar grupos de filiación política que van desde teorías marxistas hasta teorias libertarias como los de las fundaciones Hayek o Mises, o el caso de Linkedin cuyo propósito es crear lazos de tipo profesional, Livemocha, red social cuyo fin es facilitar el aprendizaje de idiomas, a través de cursos y el acercamiento e interacción con nativos de otras lenguas o en el caso de tudiabetes.org, en el cual se crean vínculos entre personas que sufren de ésta enfermedad, para compartir experiencias y mejorar sus tratamientos médicos.

¿La Intimidad, el buen nombre y la Propiedad Intelectual Son Los límites Del Derecho a La Información En Las RSV?.

Ya se había mencionado omo la propiedad intelectual desde su aparición le otorgó a las obras e innovaciones la naturaleza de bien privado que puede ser apropiado, e.g., el Estatuto de la Reina Ana en Inglaterra (McKeown, 2010). Este tratamiento ha funcionado más o menos bien, en la medida en que ha estimulado la obtención de nuevas tecnologías y dentro de los problemas que subyacen a la propiedad intelectual y que ya se mencionó son: la imperfecta noción de propiedad y la tragedia de los anti-comunes.

Con lo anterior se quiere decir que una persona que adquiere una obra, no obtendrá un derecho pleno de su propiedad sino que ese derecho es relativo o limitado, y una dificultad que esto trae aparejado es que las innovaciones y obras derivadas que resulten no se podrán llevar adelante, a menos que se cuenten con la aceptación expresa de su creador.

Pero dicha noción de protección estricta de la propiedad intelectual se ve amenazada por el surgimiento de internet, esta supone un cambio en la dinámica de incentivos, pues al mantenerse como una herramienta que permite la cooperación y no la apropiación, presiona para que haya cambios dentro de las formas jurídicas de protección a la propiedad intelectual. Uno de esos cambios es el libre licenciamiento, también conocido como copyleft (Jongitud Zamora, 2006/2007, pp. 164 - 165), en el que los creadores de obras o software otorgan el permiso de copiar la obra íntegramente, esto es, se busca proteger el derecho moral de autor, pero se deja en libertad los aspectos patrimoniales, la persona que adquiere en la web una obra o información con libre licenciamiento, sabe que lo puede copiar y la posibilidad de derivar productos de ella depende de los permisos anunciados por su creador. Por lo general, todas las innovaciones, mejoras o nuevas utilidades que hagan terceros, deben disponerse de forma gratuita al público, esto es, no puede tener un uso comercial.

Lo interesante de esto es que estas nuevas dinámicas la están haciendo los particulares, no son las instituciones del Estado quienes las crean y promueven. Dentro de los proyectos de libre licenciamiento uno de los más famosos es Creative Commons, que busca mantener a internet como un sitio de colaboración, de lo cual Alegre (2010, p. 13) sostiene que la idea de éstas licencias es preservar a internet como un "commons", esto es, un espacio en el que se permite la colaboración y evitar las restricciones que podría hacer lo que él denomina como "lógica propietarista".

480

AGO.USB Medellín-Colombia $\quad$ V. 12 №2 PP. 214- 547 Julio-Diciembre 2012 ISSN: 1657-8031 
Pero, aunque existen todas estas alternativas, ¿Qué sucedería si un persona publica una obra o software de su autoría en una RSV?, ¿Qué ocurriría si una persona publica obras de otras personas en una RSV?, ¿Qué pasaría si una persona revela secretos industriales o información sometida a reserva utilizando una RSV?.

En cuanto a la primera pregunta Baños (2009, párr. 6 - 8) sostiene que las personas que pertenecen a RSV, para poder utilizar el programa, tuvieron que realizar un contrato de afiliación o suscripción y muchos de esos contratos contemplan la cesión de derechos patrimoniales de lo que se publique en sus páginas y en otras, se estipulan cláusulas de permanencia de la información, así el usuario haya solicitado su retiro de la RSV.

Si alguien publica obras u software de otros en las RSV hay que diferenciar si tiene o no la autorización de su autor. Por ejemplo, artículos y software con libre licenciamiento autorizan a los usuarios expresamente la posibilidad de publicar la información donde lo deseen, lo cual no significa que la RSV tenga la explotación patrimonial exclusiva ya que el contenido si bien fue colocado allí por una persona, ésta no es el autor de la obra. Pero si alguien publica sin autorización la obra o software, se aplica el derecho tradicional de la propiedad intelectual, específicamente los derechos de autor, por lo tanto, se debe indemnizar al creador de la obra. El problema que esto tiene es cuando una persona que esconde su identificación real (no da a conocer su nombre real, sube los contenidos desde servidores públicos, utiliza programas para evitar el rastreo) publica en una RSV una obra de otra persona, hay una dificultad importante para que dicho individuo responda, entonces, ¿Debe responder la RSV por el contenido que infringe los derechos de autor? Esta pregunta será contestada más adelante, al final de éste acápite.

Y respondiendo a la tercera pregunta, si alguien revela información confidencial, de secreto industrial o sometido a reserva a través de las RSV, éste podría ser demandado y compelido a resarcir el daño, pero, siempre y cuando se logre localizar a la persona, de ahí que la pregunta que se formuló en el párrafo anterior se pueda extender a éste tema.

Otra dificultad que se tiene en las RSV es la protección a la intimidad y al buen nombre, muchas personas se han visto perjudicadas en su ámbito privado por que otras divulgan información sobre sus gustos comerciales a empresas, o simplemente dan a conocer información que arremete contra su vida familiar o sentimental, e incluso, en muchos casos se emite información injuriosa o calumniosa sobre alguien, vulnerando su buen nombre.

Las posibilidades de monitoreo de lo que se hace en las RSV es minúsculo por parte de los gobiernos, es tanta la información, son tantas las personas que están en RSV, muchas que lo hacen de incógnito y resulta muy dificil controlar todo ese flujo de información. Piénsese por un momento ¿Cuánta información se publica cada minuto en las RSV? Aunque no se ha encontrado una cifra que responda a esta pregunta, intuitivamente se podría decir que es muchísima; si usted pertenece a una RSV haga cálculos de cuánta información publica en el día y cuánta información le llega en ese mismo día. Ahora piense que no es sólo Usted sino millones de personas que publican datos en esa misma página web, deducirá que en un minuto es muy abundante la información que se publica en las RSV. 
Ahora bien, una buena cantidad de datos que circulan en las RSV son violatorias de la intimidad y el buen nombre de las personas. Esta afirmación, igual que la anterior, no se sustenta en cifras ya que se carecen de ellas, pues pese al rastreo no se han hallado, pero si se miran las noticias, se pueden encontrar muchas notas o reportajes en donde se expone una buena cantidad de éstos casos. Valga como ejemplo lo sucedido en La Rioja (España), en el que un sindicato de maestros denunció casos de violación a la intimidad y al buen nombre no sólo de docentes sino también de estudiantes en una RSV en la localidad de Logroño. Al parecer, dicha información fue publicada por otros estudiantes quienes alejados de todo ideal de respeto a la privacidad, emitieron imágenes y otros datos, e hicieron comentarios peyorativos y chistes de éstas personas (Libertad Digital, 2009).

Éste caso toca otro asunto interesante ¿Qué sucede cuando son personas que no han cumplido la mayoría de edad quiénes publican información que atenta contra derechos de terceros mediante las RSV? La respuesta es que se sigue el esquema tradicional, esto es, los padres responderán patrimonialmente por los daños ocasionados por sus hijos y, en el medio colombiano, las denuncias por posibles conductas punibles cometidas por menores serán conocidas por los jueces de ésta especialidad, para que determinen el grado de responsabilidad penal y en caso de ser hallados culpables, se sancione al infractor con la imposición de alguna pena.

Hay dos factores que pueden acrecentar el número de información lesiva de derechos de terceros en las RSV y que fueron explicados por Gómez (2000) para un caso diferente, como lo es el de la violencia en Colombia, pero que puede ser utilizado en éste tema. Esos dos factores son: a) Las facilidades de transferencia de conocimiento o know-how de los mecanismos en la web que han funcionado para atentar contra la intimidad de otras personas sin ser sorprendidos por las autoridades competentes (esto es, lo que muchos considerarian como apología al delito) y b) los imaginarios sociales equivocados de éxito, heroísmo o de justificación ética que tienen algunos jóvenes respecto de acciones que atentan contra el buen nombre y la identidad.

La existencia de páginas web donde se instruya en las formas de hacer ingeniería social, phishing, hacking (no se hace alusión aquí, a los ataques cibernéticos utilizados por empresas de seguridad para hacer exámenes de vulnerabilidad de algún sistema), etc., es una muestra de cómo se transfiere el Know-how de prácticas y técnicas que pueden resultar lesivas a los derechos de terceras personas. De igual forma, las múltiples páginas que tratan sobre los aspectos políticos y ético del hacking (No se quiere decir que el hactivism sea una práctica reprochable per se, ésta podría tomar esta connotación cuando se pasa de la persuasión a la acción lesiva de derechos de terceros) o que relatan experiencias exitosas de hackers que luego han sido contratados como directores de seguridad de grandes compañias o de empresas que proveen seguridad informática fruto de sus habilidades con la programación (como sería el caso de Sven Jaschan o, el creador de "The conscience of a Hacker", Loyd Blankenship), hace que lleguen nuevos adeptos que utilicen las mismas técnicas y otras mejoradas, buscando fama o contribuyendo, por medios lesivos de derechos, con alguna causa (política o ética). Las RSV no se escapan a esto, pues son muchos quienes practican estas técnicas dentro de sus plataformas y otros que publican, a través de las RSV, 
las diversas formas de hacerlo, instruyendo al público. Lo anterior dificulta aún más la labor de las autoridades.

Y ¿qué sucede si es la misma RSV la que entrega datos a empresas, por ejemplo para publicidad? La respuesta jurídica que se le ha dado a estas prácticas es la posibilidad de presentar una solicitud al usuario, para que autorice dicha acción anunciando previamente las consecuencias y riesgos de la misma (consentimiento informado), si lo hace sin la aquiescencia del o los individuos afectados, podrian ser demandados civilmente para que resarzan el daño ocasionado. Lo reprochable no es que se haga uso de la información, sino que se haga sin autorización de la persona. Así parece entenderlo por ejemplo la Agencia Española de Protección de Datos (AGPD) en España, pues la "Ley Orgánica de Protección de Datos de Carácter Personal" estipula en su artículo 6 numeral 1 que: "El tratamiento de los datos de carácter personal requerirá del consentimiento inequívoco del afectado, salvo que la ley disponga otra cosa" y en varios casos, ha tomado posición para defender este mandato de la ley, véase las resoluciones que resuelven los siguientes casos: a) B.B.B. (denunciante) vs A.A.A. Resolución: R/02556/2011 y b) B.B.B. (denunciante) vs. Little Cup, S.L. (La Tazzina) Resolución: R/00369/2012.

Ahora bien, ¿qué se puede hacer para respetar los derechos (intimidad, propiedad intelectual y buen nombre) de los usuarios que se encuentran en las RSV y de terceros? Las soluciones propuestas van desde la vigilancia absoluta y la restricción total de los datos privados y de aquellos que tengan protección por propiedad intelectual, hasta la autogestión y autoprotección de los usuarios de su propia información.

Dentro de los casos judiciales más reconocidos y que se podría enmarcar en la última propuesta, está el de la Sociedad Belga de Autores, Compositores y Editores (SABAM) vs Netlog NV en el que la primera requirió a la segunda (que es una RSV) pues consideraba que ésta permitía subir obras de su repertorio que estaban protegidas por derechos de autor. SABAM le solicitó a Netlog que impusiera un sistema que permita rastrear el contenido de la información que es allegada a la red y detectar cuál se encuentra protegida. La sala Tercera del Tribunal de justicia de la Unión Europea en sentencia del 12 de febrero de 2012, determinó que los derechos de propiedad intelectual no tiene una protección absoluta y que si se encuentra una contradicción entre éstos y otros derechos deben ponderarse y que en el caso bajo examen, se valoraron estos derechos vs los derechos de libertad de empresa, y decidió no conceder a SABAM su petición aduciendo que "dicho requerimiento judicial implicaría una vulneración sustancial de la libertad de empresa del prestador de servicios, dado que le obligaría a establecer un sistema informático complejo, gravoso, permanente y exclusivamente a sus expensas" y de igual forma manifiesta el riesgo a la libertad de información pues "se corre el riesgo de que el citado sistema no distinga suficientemente entre contenidos lícitos e ilícitos, por lo que su establecimiento podría dar lugar al bloqueo de comunicaciones de contenido lícito".

El otro grupo de propuestas buscan una protección rígida de los derechos, imponiéndole al Estado y a las empresas que manejan RSV la obligación de monitorear, detectar y suprimir contenido en la web antes que un juez dictamine que dicho contenido es lesivo. Como ejemplo 
podemos citar el caso de Diana Cornwell (Stern, 2012), en el que al parecer una RSV cerró su cuenta debido a que publicó imágenes de su hijo que sufre de Síndrome de Down y al parecer, la politica de la empresa es que no deben aparecer estas imágenes por posibles violaciones a sus derechos. Es evidente que en éste caso hubo un error, generado por el rastreo de la información y la supresión ex-ante del contenido, lo cual generó una lesión a la señora Cornwell.

Otro ejemplo, es el de los proyectos de ley que fueron presentados en varios países y que no fueron aprobados (excepto la ley francesa, que, de las mencionadas, fue la única que se aprobó), entre los que se encuentran: SOPA y PIPA (en Estados Unidos), SINDE (en España), DORING (en México) y HADOPI (en Francia). Dichos proyectos fueron tramitados en los congresos de éstos países debido a la preocupación de algunos grupos que luchan en pro de la defensa de la propiedad intelectual y que pretendian crear un marco institucional de defensa de los derechos de los creadores y también fue impulsada por buscadores de renta (rentseeking), que querían obtener más ganancia a costa de la constitución, fortalecimiento y protección estricta que le dan los gobiernos al fruto de la creatividad humana.

Todas estas normas tienen en común el establecimiento de mecanismos de rastreo de información y el cierre de páginas que sean consideradas atentatorias contra derechos de terceros, especialmente con la creatividad. La más famosa de éstas es la denominada ley SOPA (Stop Online Piracy Act) que pretendía proteger las creaciones estadounidenses de cualquier intrusión nacional o extranjera, esto es, el ámbito de aplicación de la ley excedería los límites territoriales. Por ejemplo, en la sección 102 de la ley, denominada: "Action by attorney general to protect u.s. customers and prevent u.s. support offoreign infringing site", se establecieron medidas preventivas, buscando dificultar el acceso a nombres de dominio foráneas que sean consideradas lesivas, algo similar a lo que hace China y que mereció tantas críticas por la diplomacia estadounidense.

Este tipo de iniciativas hizo que se enfrentaran la industria cinematográfica que apoya los proyectos de ley SOPA y PIPA y la industria informática, que en su mayoría se opone a estas iniciativas legales, ya que se verian seriamente perjudicadas. Ambas partes utilizaron todas las estrategias posibles buscando su propio beneficio y una de las herramientas utilizadas fue el cabildeo (Rodriguez, 2012) o reent seeking. Pero la presión para que no fueran votados los proyectos de ley fue tan fuerte que tuvieron que archivar las iniciativas.

Para nadie es un secreto que el uso de las nuevas tecnologías e incluso de las RSV, trae aparejado algunos peligros, o como lo sostiene el mismo Paul Virilio, "accidentes" (ya fue citado en la introducción de éste artículo), y así parece entenderlo también algunos gobiernos y expertos en el tema. Por ejemplo, la Asamblea General de la ONU en resolución 3384 del 10 de noviembre de 1975 emitió la "Declaración sobre la utilización del progreso científico y tecnológico en interés de la paz y en beneficio de la humanidad" y dentro de sus consideraciones se menciona: "tomando nota también con inquietud de que los logros científicos y tecnológicos pueden entrañar peligro para los derechos civiles y políticos de la persona o del grupo y para la dignidad humana". Para prevenir esto, en el numeral 6 de la misma Declaración se contempla: 
Todos los Estados adoptarán medidas tendientes a extender a todos los estratos de la población los beneficios de la ciencia y la tecnología y a protegerlos, tanto en lo social como en lo material, de las posibles consecuencias negativas del uso indebido del progreso científico y tecnológico, incluso su utilización indebida para infringir los derechos del individuo o del grupo, en particular en relación con el respeto de la vida privada y la protección de la persona humana y su integridad fisica e intelectual.

Lo anterior constituye un claro mandato a los Estado para que adopten medidas tendientes a la protección de los derechos de las personas en el uso de las nuevas tecnologías, esta misma apreciación es compartida por los creadores del "Memorándum sobre la protección de datos personales y la vida privada en las redes sociales en internet, en particular de niños, niñas y adolescentes" (Albornoz et al., 2009), quienes en el numeral 2 del acápite de las "Recomendaciones para los Estados y entidades educativas para la prevención y educación de niñas, niños y adolescentes" y en donde se reafirma que toda medida que implique control de la información debe respetar el "principio de proporcionalidad", esto es, la medida debe ser "adecuada al fin perseguido" y debe probarse "que no existe otra medida que permita obtener los mismos resultados y sea menos restrictiva de los derechos".

Pero ¿Se justifica un papel estricto del Estado en el control de internet y específicamente de las RSV? La respuesta es: "no"; si bien las tecnologías de la información y comunicación implican retos, debido a los casos de abuso y violación de derechos perpetrados por algunas personas, esto no debe llevar a que los estados asuman un papel activo y estricto en el control de la internet. Si bien se mencionó que los gobiernos tradicionalmente han intervenido para corregir las fallas del mercado, en este caso, buscando proveer de información a la humanidad, también se debe reconocer que éstas entidades también se equivocan y en muchas ocasiones de forma más gravosa u onerosa (Krause, Zanotti y Ravier, 2007, p. 283325; Boehm, 2005, p. 45): "Cuando apelamos a las fallas del mercado, deducimos que el Estado debe intervenir; pero cuando lo hace, produce a veces efectos indeseables o genera intervenciones inconsistentes o inconvenientes; es decir, el Estado también falla" (Bejarano, 1999, p. 89 - 90).

Piénsese por un momento, si un Estado asume el control total de internet, debe asumir unos costos. Los dispositivos que se deben adquirir o que se deben crear para poder manejar la información y el personal (aumento de la burocracia) que deben disponer para ello, deben ser pagados por el erario público; los errores que se cometan pueden dar lugar a procesos de responsabilidad del Estado que también deben ser pagados con dinero público; si a esto se le suman los costos políticos que tiene la posible existencia de casos de censura, y los costos que para la creatividad e innovación tiene la disminución del flujo de información, llevaría a concluir, sin lugar a equívocos, que la intervención de los gobiernos podría ocasionar un costo social altísimo, con un agravante, que dicho control puede ser ineficiente en cuanto a que no se logre el fin deseado, ya que existen y se pueden crear una serie de dispositivos o programas que logren burlar los sistemas elaborados por el o los Gobiernos.

Lo anterior permite concluir que pese a los problemas que trae aparejado internet, la pretensión por el control total puede tener costos altísimos, además los Estados cuando tienen un poder exacerbado tienden a abusar de él, recuérdese lo ocurrido en la Alemania Nazi, la Chile de Pinochet, La URSS de Stalin, etc. 
En este momento, China se encuentra aplicando mecanismos de restricción de la información en Internet, eso le ha ocasionado mucha resistencia y críticas internacionales, por ejemplo, al momento de culminar éste trabajo, se encontró la noticia de que Google está ejecutando estrategias para burlar el "sofisticado aparato de censura del Gobierno de Pekín con un nuevo sistema que informa a los internautas chinos cuándo introducen en su buscador un término que está 'bloqueado' y les aconseja qué palabra o carácter chino deben utilizar" (EFE, 2012).

El temor no es infundado. Si se aprueban proyectos como SOPA, PIPA, SINDE o DORING, los Estados podrían tener a su servicio un poder tan grande y oneroso, que podría correrse el riesgo de que abusen de él, que hagan censuras e incluso que se reduzca la cantidad de información que circula en internet, lo cual, se reitera, trae un costo social muy grande. Recuérdese por ejemplo los perjuicios generados por el cierre de Megaupload y el arresto de Kim Dotcom (BBC Mundo, 2012) sobre los usuarios que subieron información privada y que no es violatoria de los derechos de propiedad intelectual. Si bien lo que se pretendia con la medida es frenar los abusos contra los derechos de autor y evitar el lavado de dinero, el hecho de cerrar la página sin aviso previo, y sin mecanismos que compensara las pérdidas de quienes de buena fe guardaron información en dicha página, hizo que muchas personas en el mundo se vieran afectadas, pues no podrán disponer de su información, además, la medida es ineficiente pues no se cumple el fin propuesto, ya que las conductas por las cuales se cerró Megaupload no se van a dejar de hacer, por el hecho de cerrar dicha página web, esto es, el costo social, en éste caso, es mayor que los beneficios sociales generados.

Tampoco se cree conveniente que las empresas dueñas de las RSV, reemplacen a los gobiernos y asuman unilateralmente éste control, recuérdese el caso ya expuesto de Diana Cornwell, donde se abusó de su situación al cerrarle su cuenta por publicar la foto de su hijo. Este tipo de controles ejecutados por particulares también pueden devenir en censura. Ni el Estado, ni los particulares pueden tomar éste tipo de iniciativas que restringen la información, pues nos veríamos abocados al peligro del "Gran Hermano" o "la policía del pensamiento" y de la vigilancia total descritos por George Orwell (s.f) en su obra titulada: "1984", además nos llevaría, como lo afirma Clay Shirky (2012), a que los usuarios de internet (y especificamente de las redes sociales) asuman un rol pasivo de "solo consumo" y no proactivo tendiente a la creatividad.

Cualquiera de los dos esquemas: el del control de la información de las RSV por el Estado o por particulares es ineficiente, ya que no resuelven el problema, pues: "Por cada persona inteligente que se molesta con crear un esquema de incentivos, existe un ejército de gente, inteligente o no, que inevitablemente invertirá incluso más tiempo en tratar de burlarlos" (Levitt y Dubner, 2006, p. 34), sobretodo en internet, mírese por ejemplo el caso de Anonymous que en protesta por las demandas que interpuso la Sociedad Alemana de Compositores Musicales contra la empresa Youtube por la reproducción de videos de material protegido por la Sociedad, bloqueó la página web de ésta Entidad (EFE, 2011).

Entiéndase que aquí no se está asumiendo una postura anárquica, simplemente se quiere decir que en éste caso específico, esto es el tratamiento de la información, el Estado no podría tomar un papel activo (de control total), pues de hacerlo se podría generar un mayor daño a la 
sociedad, se habla de un papel pasivo, ex post, que se acuda a la justicia en primera medida para juzgar los casos de abuso.

Para buscar mejores soluciones se propone un marco regulatorio institucional en el que los Gobiernos permitan el flujo y la creación de nueva información y una alianza con las empresas y otros estamentos sociales promoviendo la cooperación y dos formas combinadas de protección de datos: a) brindar herramientas de autoprotección, esto es, que sean los mismos individuos quiénes decidan sobre el tipo de seguridad que quieren sobre sus datos en las RSV y que se creen sistemas que impidan la intrusión de otros programas en sus plataformas y b) la persuasión, a través de la educación, para convencer a las personas de las ventajas de actuar éticamente, de no apropiarse de trabajos o información elaborados por otras personas y de la necesidad de proteger los datos privados para evitar abusos. Esto último, para prevenir los atentados contra la libertad de información, la propiedad intelectual y los derechos a la intimidad.

Por fortuna existen iniciativas privadas como los libres licenciamientos (como el GPL, Open Audio License, Creative Commons, Against DRM 2.0, LDGPL, OFL, entre otros), que buscan proteger los derechos morales de los creadores y facilitar el uso de la información para crear obras derivadas, lo que en últimas incentiva la colaboración entre personas dinamizando la creatividad humana.

Se expone como algo positivo lo anterior, pues son formas privadas que intentan redefinir y recrear el derecho de propiedad intelectual a través de iniciativas privadas que atempere la protección estricta y permita la colaboración y facilite la innovación.

Éste artículo comparte la apreciación del profesor Enrique Bour (2008/2009, p. 753 y 754) cuando afirma que los juristas tienen la tendencia a escribir sobre las instituciones legales de sus países, lo que hace que, por regla general, aquello que escriben no es aplicable en cualquier situación, lo cual reduce el interés por su estudio, a menos que se quiera hacer un análisis de derecho comparado. Siguiendo esta idea, lo que se afirma en éste artículo, podría ser aplicable a cualquier país, pero se acudirán a enunciar algunos casos ocurridos en Colombia que refuerzan las aseveraciones hechas en los capítulos precedentes.

Ya se expuso el intento de varios gobiernos por regular el internet en diversos países. En Colombia se pretendió lo mismo, con la propuesta conocida como: "Ley Lleras" (proyecto de ley 241 de 2011), denominada así debido al segundo apellido de su creador: Germán Vargas Lleras, Ministro del Interior y Justicia en la presidencia de Juan Manuel Santos Calderón. El fundamento para impulsar éste proyecto es que en la web, tanto el software, como otro tipo de obras (literarias, artísticas, académicas, etc.) estaban siendo utilizadas por los usuarios de internet, sin autorización de sus creadores.

Teniendo claro que los autores o titulares de derechos tienen pleno control sobre la explotación de sus obras en el medio digital, es posible deducir que en las redes informáticas pueden presentarse actos de piratería, es decir actividades que impliquen explotación de obras sin contar con la previa y expresa autorización del autor o titular de derechos patrimoniales. En otras palabras, ha de entenderse por pirateria en Internet o ciberpirateria, 
la explotación de obras, por ejemplo la puesta a disposición y descarga, sin contar con la previa y expresa autorización del legítimo titular de los derechos... En consecuencia el proyecto de ley en comento proporciona elementos disuasivos y adecuados para proteger de manera efectiva en Internet y otras redes informáticas a los creadores de obras en nuestro país, siendo a su vez congruente con las obligaciones que a través de tratados internacionales ha adquirido el gobierno nacional. (Vargas Lleras, 2011).

Dentro de las acciones que se querían implementar, encontramos en los artículos 7, 9, 10 y 11 de éste proyecto, la posibilidad de que los prestadores de servicio, incluidas las RSV, crearan mecanismos para detectar y retirar contenido de sus bases de datos que sean lesivos a los derechos de propiedad intelectual.

La presión ejercida para conseguir la no aprobación del proyecto, es comparable a lo sucedido en EEUU con las denominadas SOPA y PIPA, e incluso hubo manifestaciones de grupos hacktivistas extremos que propenden por la libertad de internet, como por ejemplo "Anonymous" (Elespectador.com, 2011).

Posterior a esto, el día 13 de abril de 2012, se aprobó el proyecto de ley 201 de 2012 conocida en los medios de comunicación como "Ley Lleras 2.0", la que se convirtió en la ley 1520 de 2012. Esta ley estuvo en la palestra pública pues para muchos es la continuación del proyecto de ley 241 de 2011 (el cual ya fue explicado) que impone controles a la información que circula en internet y aunque en esta norma se prohíbe la transmisión por medios electrónicos de copias hechas sin autorización de sus titulares y la prohibición de retransmitir por internet programas de televisión y pese a los problemas jurídicos que pudiera tener dicha norma, los impactos sobre el control de la información son mínimos o casi nulos por lo tanto, no se comparte la apreciación de que esta norma es similar a PIPA, SOPA, SINDE o Ley Lleras, al menos no en el sentido de establecer mecanismos preventivos de protección.

Pero las violaciones a los derechos de terceros en las RSV no sólo se enmarcan dentro de la Propiedad Intelectual. Uno de los caso más sonado en Colombia en el que se involucra a una red virtual como medio utilizado para la violación de la intimidad y derechos de terceros es el caso de las amenazas por Facebook al hijo del Ex-presidente Álvaro Uribe Vélez, Jerónimo Uribe. Con ayuda del FBI (Federal Bureau of Investigation de Estados Unidos), la Fiscalía General de la Nación instauró una denuncia penal contra el joven Nicolás Castro por considerar que existió responsabilidad penal del joven en éste caso, pero tanto el a quo como el Tribunal Superior de Bogotá (ad quem) exoneraron de responsabilidad a ésta persona por falta de pruebas (Elespectador.com, 2012).

En el periódico "El Tiempo" del día 3 de diciembre de 2009, que cubrió la noticia de las amenazas al hijo del ex-mandatario a través de una RSV, se relatan otros casos similares al descrito en el párrafo anterior:

El DAS investigó el año pasado 28 casos de amenazas en internet (dos de ellos contra Gustavo Petro) y este año, otros 18. Las amenazas de este año llegaron contra personajes como Petro, Carlos Gaviria, la Dirección del Polo Democrático, la Dirección de Derechos Humanos del 
Ministerio del Interior, la Universidad del Valle, el Fondo Nacional del Ahorro, entre otras. En varios casos se llegó a ubicar el sitio donde escribieron las amenazas: uno de ellos, por ejemplo, resultó ser un café internet cercano a una sede del Polo en Bogotá. Pero el caso no fue judicializado por los afectados. (Eltiempo.com, 2009).

La problemática de éste asunto es el anonimato que en la mayoría de éstos acontecimientos reviste a los responsables, pero no todos los casos ocurridos tienen que ver con violación a la intimidad o a los derechos de propiedad intelectual, se trata de una amplia gama de bienes jurídicos que pueden verse afectados, como por ejemplo, la vida. Tal vez éste sea el caso de la joven universitaria Ana María Chavez Niño, quien fuera contactada a través de una RSV por dos individuos que se ganaron su confianza. Al parecer, ella los invitó a su residencia y allí fue asesinada por ellos, para poder hurtar los objetos de valor que tenía en su residencia (Caracol, 2009).

Para concluir con los casos, se relatará el conocido por la Corte Constitucional colombiana en sentencia T-713 del 8 de septiembre de 2010 en donde estudiantes crearon una página en una RSV donde pedían la renuncia de la rectora de una institución educativa, al parecer la Entidad endilgó la responsabilidad a uno de los estudiantes y lo apartó de la institución, y éste por intermedio de sus padres interpuso una acción de tutela, la cual prosperó y en donde la Corte Constitucional, pese a que advierte que los abusos y delitos en las RSV ha aumentado, falla en favor del menor ordenando a la institución el reingreso del estudiante, si así él lo quisiere.

Aunque todos estos casos pueden generar temor en algunas personas, por el incremento de conductas lesivas en las RSV y además, por la "invisibilidad" (o anonimato) que se generan en internet, similar al relatado en el "anillo de Giges" (Platón, 50 - 88), se considera que la intervención previa del Estado no es la mejor, ni la única solución, pues los actos violatorios de derechos pueden continuar e incluso aumentar bajo un esquema rígido de vigilancia por parte del Estado, pero, por ejemplo, la educación en valores podría ser más eficiente que la intervención del Estado y por lo tanto, una de las herramientas a la cual apelar. Valga citar del trabajo de Levit y Dubner (2006, p. 54 - 60) el relato que hacen del experimento del economista Feldman de las galletas que deja en varias empresas con una caja donde las personas pueden depositar su dinero. En éste experimento se demuestra que los incentivos morales son tan fuertes que una persona puede cumplir las normas, así no lo estén viendo, por lo tanto, si un individuo es instruido y se persuade para que considere que algunos deberes, como en éste caso, el de "no dañar a terceros" o "respetar la autoría de otros" son importantes, lo más probable es que los cumpla, así esté en el anonimato, es decir, sin ser visto en la web.

Se quiere culminar éste acápite poniendo de presente que si bien, existen propuestas privadas como los libres licenciamientos que intentan renovar todo lo relacionado con los derechos de propiedad intelectual, "parece" que dichas iniciativas no son muy conocidas en el país. Esta es la intuición que se tiene luego de conocer los datos parciales de la investigación que se lleva a cabo en la Universidad de San Buenaventura Seccional Medellín (USBMED), denominada: "Las redes sociales virtuales, los buenos usos". En una encuesta realizada a docentes, empleados y estudiantes de la Institución de Educación Superior, se les indagó en 
una de las preguntas por el conocimiento del libre licenciamiento y de 518 instrumentos que se llevan sistematizados hay una clara tendencia que demuestra el desconocimiento de estas propuestas. Sólo 57 personas aseguran conocer el funcionamiento del libre licenciamiento, se trata del $11 \%$ de la población universitaria. Si esta encuesta se hiciera en varias regiones del país, tomando una muestra poblacional significativa, y los resultados arrojados siguieran la tendencia de la USBMED, se podría confirmar la afirmación que se hace al inicio del párrafo, de igual forma sucedería si se hiciere extensiva en todo Medellín la encuesta.

Aunque los anteriores datos son parciales, arrojan una tendencia muy marcada y difícil de revertir en las encuestas que faltan por sistematizar.

Es interesante el resultado, pues las personas encuestadas son universitarios, población que debería tener conocimiento de éste tipo de iniciativas (libres licenciamientos), debido a que a ellos se les exige en mayor grado, que inicien propuestas de investigación y de innovación, por lo tanto se debería tener claro los temas relacionados con la propiedad intelectual.

Pese al desconocimiento existente, se espera que con el acontecer, surjan alternativas que buscan renovar el derecho, como los libres licenciamientos, y que éstas sean más populares, sobre todo en Colombia.

\section{Conclusiones.}

Aquí se deben indicar varias cosas:

Las RSV no pueden ser vistas como un aspecto negativo de internet, pues no sólo son utilizados para hacer daños, sino que es una herramienta que facilita la comunicación, promueve las relaciones sociales y provee mucha información y esto es valioso para incentivar la innovación, la creación y ejecución de planes de negocio y el aprendizaje de otros idiomas e incluso de mejores técnicas de producción.

Pese a los casos de abusos en las RSV, sobretodo en Colombia, la represión y manejo absoluto de la información por parte de los Estados o de las firmas que son dueñas de las RSV, pueden tener consecuencias negativas y altos costos sociales, como por ejemplo, la disminución de información disponible y actos de censura.

Colombia, al igual que otros países, han optado por extremar la defensa de la libertad individual al no aprobar propuestas legislativas como la denominada "Ley Lleras" o proyecto de ley 241 de 2011, lo cual es interesante, ya que la presión social le envió un claro mensaje a los gobiernos, indicándoles que es preferible la libertad de información a controles preventivos que podrían llevar a la represión y la censura.

Es evidente el conflicto marcado entre los sistemas de propiedad intelectual tradicionales (propietarismo), los que propenden por una absoluta libertad y los de licenciamiento libre en el dominio y control de internet, específicamente en las redes sociales, ésta última está en fase de desarrollo y podría resultar vencedora por ser una propuesta intermedia entre las propuestas extremas, además que se constituye en una "regla decente" (Stordeur, 2008, p. 43 
- 45) pues incentiva la colaboración y a su vez reconoce el derecho moral de los creadores.

Preocupa el poco conocimiento que la comunidad universitaria en Medellín puede tener acerca de los libres licenciamientos ya que es un tema atinente a la propiedad intelectual y se espera que las Universidades sean lugares donde circulen las ideas y florezca la creatividad y si no se conoce la forma de protegerla o los derechos que ellas traen aparejadas, no se estaría haciendo una buena labor. 


\section{Referencias.}

Proyecto de Ley 241 de 2011 "Por el cual se regula la responsabilidad por las infracciones al derecho de autor y los derechos conexos en Internet”, Ley 241 de 2011 (2011).

Proyecto de Ley por el cual se regula la responsabilidad por las infrecciones al derecho de autor y los derechos conexos en internet, Ley 241 (Congreso del a república de Colombia 2011).

Aguiar, F. (2008). Libertad, justicia y juegos. Obtenido de http:/ / digital.csic.es/bitstream/10261/2071/1/12-06.pdf.

Alegre, M. (2010). El dinero y la justicia: George Priest y el análisis económico del derecho. Buenos Aires: Yale Law School y Universidad de Palermo.

Baños, J. (6 de Mayo de 2009). Los derechos de propiedad intelectual y las redes sociales. Obtenido de http: / / www.legaltoday.com/ practicajuridica/civil/prop._intelectual/los-derechos-de-propiedad-intelectual-y-las-redessociales

BBC Mundo. (20 de Enero de 2012). Cuatro claves del cierre de megaupload. Obtenido de semana: http://www.semana.com/mundo/cuatro-claves-del-cierremegaupload/170634-3.aspx .

Bejarano, J. (1999). Los nuevos dominios de la ciencia económica. Cuadernos de economía, 78-91.

Bergara, M. (1999). Costos hundidos endógenos y la introducción de nuevos productos: el sistema bancario uruguayo. Revista de Economia, 5-38.

Boehm, F. (2005). Corrupción y captura en la regulación de los servicios públicos. Economia Institucional, 245-263.

Bour, E. (2009). Lecturas de Metodología económica y Derecho. Obtenido de http:/ / www.ebour.com.ar/index.php?option=com_content\&task=view\&id=156\&Ite $\operatorname{mid}=56$.

Canavese, A. (2007). Temas en el análisis económico de los derechos de propiedad. Revista de Economía Política de Buenos Aires, 31-36.

Caracol. (30 de Octubre de 2009). Joven universitaria fue asesinada por dos hombres que conoció a través de Facebook. Obtenido de caracol: http:/ / www.caracol.com.co/noticias/bogota/joven-universitaria-fue-asesinadapor-dos-hombres-que-conocio-a-traves-de-facebook/20091030/nota/902916.aspx.

Coase, R. (1992). El problema del costo social. Revista Estudios Públicos, 81-134.

Coloma, G. (2003). La tragedia de los comunes y la tragedia de los anticomunes: una reinterpretación. Anales de la Academia Nacional de Ciencias Económicas, 173-180. 
EFE. (22 de Agosto de 2011). Anonymous bloquea web de sociedad de compositores musicales alemanes. Obtenido de Revista dinero:

http://www.dinero.com/actualidad/noticias / articulo/anonymous-bloquea-websociedad-compositores-musicales-alemanes / 133733.

EFE. (2 de Junio de 2012). Google consigue burlar censura del gobierno chino. Obtenido de Dinero: http://www.dinero.com/negocios/tecnologia/articulo/google-consigueburlar-censura-del-gobierno-chino/ 152503.

El espectador. (21 de Agosto de 2011). Las protestas de Anonymous. Obtenido de elespectador.com: http://www.elespectador.com/opinion/editorial/articulo293156-protestas-de-anonymous.

El espectador. (16 de Mayo de 2012). Ratifican en segunda instancia absolucion contra Nicolas Castro. Obtenido de elespectador.com:

http:/ / www.elespectador.com/noticias/judicial/articulo-346575-ratificansegunda-instancia-absolucion-contra-nicolas-castro.

El tiempo. (3 de Diciembre de 2009). Detenido por amenazas en Facebook contra hijo de Uribe aseguró que fue una broma. Obtenido de eltiempo.com: http://www.eltiempo.com/archivo/documento/CMS-6735011.

Gonzalez Alorda, A. (27 de Mayo de 2012). Innovación = Colaboración 360 . Obtenido de Portafolio: http:/ /www.portafolio.co/opinion/innovacion-colaboracion$360 \% \mathrm{C} 2 \% \mathrm{~B} 0$.

Higueras, G. (28 de Agosto de 2005). India, de elefante a tigre. Obtenido de El país: http://elpais.com/diario/2005/08/28/negocio/1125233542_850215.html.

Jongitud Zamora, J. (2007). Contradicciones de la Globalización: surgimiento del Copyleft. Revista Telemática de Filosofía del Derecho, 141-174.

Kinsella, S. (2001). Against Intellectual Property. Journal of Libertarian Studies, 1-53.

Krause, E. (2007). Elementos de economia politica. Buenos Aires: La ley.

Levitt, S. D., \& Dubner, S. J. (2006). Freakonomics. Barcelona: Ediciones B.

Libertad Digital. (14 de Enero de 2009). Un sindicato denuncia la violación de la intimidad de profesores a través de Tuenti. Obtenido de Libertaddigital.com: http:/ / www.libertaddigital.com/internet/un-sindicato-denuncia-la-violacion-de-laintimidad-de-profesores-a-traves-de-tuenti-1276348168/.

Mateos Aparicio, M. (2012). Sitios de Redes Sociales y Mediación en procesos de enseñanzaaprendizaje. Obtenido de Revista Dinámica, Innovación y Multimedia: http://dim.pangea.org/revistaDIM22/revista22redesymediacion.htm. 
Intimidad y Propiedad Intelectual en las Redes Sociales: el Caso Colombiano.

McKeown, M. (2010). Happy birthday Statute of Anne: the dance between the Courts and Congress. Berkeley Technology Law Journal, 1145-1174.

Mejia, A. (2001). Desaparece la Biblioteca de Alejandría: ¿Pasto de las llamas o víctima del tiempo? Revista La Tadeo, 38-41.

Organizacion de Estados Americanos. (2011). Declaración Conjunta sobre Libertad de Expresión e Internet. Obtenido de oas.org: http://www.oas.org/es/cidh/expresion/ showarticle.asp?artID=849\&lID=2 .

Perez Luño, A. (2004). Internet y los Derechos Humanos. Derecho y Conocimiento: anuario juridico sobre la sociedad de la información y del conocimiento, 101-121.

Platon. (1996). La Republica. Bogota: Panamericana.

Rodriguez, S. (21 de Enero de 2012). Todos contra Hollywood. Obtenido de Elmundo.es.: http: / / www.elmundo.es / blogs / elmundo/catalejo/2012/01/21/todos-contrahollywood.html.

Shapiro, C., \& Varian, H. (1998). Versioning: the smarth way to sell information. Harvard Business Review, 107-114.

Sherwood, R. (1995). Propiedad Intelectual y desarrollo económico: una nueva estrategia para competitividad científica y tecnológica. Buenos Aires: Heliastas.

Shirky, C. (18 de Enero de 2012). Sopa and Pipa would create a consumption. Obtenido de The Guardian:

http:/ /www.guardian.co.uk/commentisfree/cifamerica/2012/jan/18/sopa-pipaconsumption-only-internet.

Stern, J. (25 de Abril de 2012). Facebook error forced mother to remove photos of her child with down Syndrome. Obtenido de ABC News:

http: / / abcnews.go.com/blogs / technology/2012/04/facebook-error-forcedmother-to-remove-photos-of-her-child-with-down-syndrome/.

Stordeur, E. (2008). Coordinacion social espontanea, juegos y experimentos: una nota introductoria. Revista de Instituciones, Ideas y Mercados (RIIM), 33-71.

Usategui, J. M. (2000). Economía de la Información. Bilbao: Universidad del País Vasco.

Villota Hurtado , O. (2008). La propiedad intelectual analizada desde la economia de la informacion. Codice, 25-34.

Virilio , P. (1998). Estética de la desaparición. Barcelona: Anagrama.

Virilio, P. (1995). Dromología: La lógica de la Carrera. Revista Letra Internacional, 34-40.

Virilio, P. (1997). El Cibermundo, la Politica de lo Peor. Madrid: Theorema y Cátedra.

494

AGO.USB Medellín-Colombia V. $12 \quad N^{\circ} 2$ PP. 214- 547 Julio-Diciembre 2012 ISSN: 1657-8031 
${ }^{2}$ El presente trabajo, hace parte, como uno de los resultados parciales, de la investigación denominada: "Redes sociales virtuales, el buen uso", perteneciente al grupo de investigación GIDPAD (Grupo Interdisciplinario para el Desarrollo del Pensamiento y la Acción Dialógica) de la Universidad de San Buenaventura Seccional Medellín. Fue financiado por la misma Universidad. 